\title{
Reading different literature helps one to learn to listen
}

\author{
Donatella Lippi
}

Received: 3 February 2014/Accepted: 21 April 2014/Published online: 31 May 2014 (C) SIMI 2014

Cervellin et al. [1] discuss two different methods used in clinical judgement: Gestalt perception and Bayesian principles, synonymous with intuition and analytical approach, which seem to be antithetical only at a first glance. They observe that their integrated application can improve the results of diagnosis and therapy, communication and decision-making. The demonstration of this assumption is the final aim of the article, which contains many original quotations [2,3].

At the same time, the authors expose the necessity of a more internalized education, starting from the academic medical curriculum, pointing the finger at a deep gap in the current education of doctors, i.e., the lack of a human/ humanistic approach to medicine. Before Gestalt theory was developed, and before the adjective "Bayesian" became part of the statistical lexicon, clinical judgement was based on a special attitude, which Pierre Jean Georges Cabanis (1757-1808), one of the most important protagonists of the clinical transformation of medicine, which occurred in the period of the French revolution, described as a sort of empathy that develops between doctor and patient [3]. Through this attitude, the doctor overcomes mere theoretic knowledge, and relies on his practical skills, placed in a kind of instinct, perfected by the custom. Identifying himself in this way with the patient, associating himself to his suffering with the readiness of a sensitive imagination, the doctor captures at a glance the disease, and is able to catch, all at once, all its elements: "En médecine, tout, ou presque tout dependant du coup-d'-œil et d'un heureux instinct, les certitudes se trouvent plutôt dans les sensations mêmes de l'artiste, que dans les

D. Lippi $(\square)$

University of Florence, Florence, Italy

e-mail: donatella.lippi@unifi.it principes de l'art" [4]. Cabanis' affirmation remains valid even now, after two centuries of scientific discoveries, which have permitted fundamental practical applications, however, very often clouding the human meaning of clinical medicine.

In this framework, the keywords are empathy and intuition. Intuition derives from Latin intuēri, from "in + tue ri", "to look at", and describes a natural ability or power that makes it possible to recognize something without any proof or evidence: it is a sort of feeling, based on experience and on continuous training, improved by personal attitude.

Despite its linguistic roots in ancient Greek, the concept of empathy is of recent intellectual heritage: the German term Einfühlung, "feeling into", by the end of the nineteenth century was in German philosophical circles understood as an important category in philosophical esthetics, but it was transformed by Theodor Lipps (1851-1914) into a central category of the philosophy of the social and human sciences [5]. Empathy, broadly speaking, can be considered as a process of interaction and of identification, between consciousness and unconsciousness: it is a sort of emotional harmony and adhesion to life experience and to the needs of the others. The development of this attitude in medicine implies a change of mentality, starting from the inversion of the acronyms, doctors are accustomed to use.

The first step in fact is the overcoming of the apparent contradiction between Evidence Based Medicine and Narrative Based Medicine, which is mirrored in the eternal problem about the definition of medicine as a science or as an art. No such thing as THE Evidence Based Medicine (EBM) or THE Narrative Based Medicine (NBM) exists: there is only one medicine for the person, but there are Medicine Based Evidence (MBE) and Narrative Based 
Evidence (NBE), which must be combined, in order to reach the Patient Oriented Evidence that Matters (POEMs) [6].

Educating to this combined approach is a hard duty and the great challenge of current medicine, and it implies the overcoming of the dualistic setting of clinical judgement [7].

This Manichaean perspective, according to the authors' point of view, can be considered the legacy of "ancient and modern philosophical and scientific statements, such as the concepts of experiment (Francis Bacon 1561-1626 and Galileo Galilei 1564-1642), repetition of observations (David Hume 1711-1776), comparison of results (John Mills 1806-1873), and finally, randomization (Ronald Fischer 1890-1962)" [1]. As a matter of fact, the information derived from technology is absolutely crucial to science and medicine, but it provides only a partial understanding of the patient, as it helps explain (erklären), not understand (verstehen). This problem may have many objective, factual reasons; however, the ancient Indian story about a group of five blind men who were asked to describe an elephant is illuminating.

The story is told by the Italian journalist Tiziano Terzani, in his book "One more ride on the merry-go-round": in his book, Terzani deals with his disease, a cancer which eventually led to his death in 2004, describing his travels through different countries and civilizations, looking for a cure and for a new vision of life [8]. After having tried many treatments, encompassing the most innovative therapies in the Memorial Sloan-Kettering Center and alternative medical cures in the Far East, Terzani offers a brilliant example of the limits of current medicine, using the story about the five blind men and the elephant. According to this tale, the first blind man grasps the elephant by its legs and says that an elephant is like a temple, and these are its columns. The second man strokes his trunk and declares that the elephant is like a serpent. The third man feels the elephant's stomach and reports that the animal is like a mountain. The fourth touches an ear, and the elephant turns out to be similar to a fan. The last blind man grabs the elephant's tail and announces that the elephant is like a whip. Terzani states that every definition contains some truth, but the elephant is not described by any of these men as it really is. He compares his excellent doctors at the Memorial Sloan-Kettering Cancer Center to those five blind men, because if a physicist, a chemist, a biologist and a zoologist were asked to provide a scientific description of an elephant, they would end up giving four totally different portrayals. This illustrates the problem of scientific knowledge: it is precise, it is exact, it is ready and willing to substitute current theories with new ones or vice versa, but it is also permanently limited in its comprehension of reality [9].
Reaching a different, overall understanding of matters requires, in fact, a special culture and a particular empathy, which only seldom are considered in medical education. Empathy, however, is an attitude, not a skill: this is why it cannot be taught nor learned, but it can in someways, be nurtured.

The authors ask: "is it possible to teach students and young doctors how the Gestalt perception can be enhanced and improved? In our practical experience, this remains an unresolved issue" [1].

As a teacher of history of medicine and medical humanities, I would like to share my experience with the authors: with my students, I have adopted the practice of reading classic literature, as a pivotal method to learn how to practice narrative medicine, a sort of special training with virtual patients.

Everyone who aspires to be a physician in fact ought to be intimately familiar with the classics, which can enhance the work and the life of every physician, in order to always be a "student of the human condition", going beyond textbooks and scientific journals [10]. The greatest feature of a true physician in fact is to be educated and competent (Bayesian principles), but also curious, intuitive, and empathetic (Gestalt principles). These latter aptitudes are not developed by only reading medical school textbooks and scientific journals, but they can be cultivated through the encounter with a work of literature. Nothing is more helpful to enlighten and improve the physician's humanity and quality, which cannot be evaluated by administering a multiple-choice test.

Some doctors have read these works during their undergraduate years, in particular if they have had a classics background, but most of them preferred to strengthen their knowledge in biological science, losing an important opportunity for their education in very important years of their lives. Among the classic mandatory works a doctor ought to be familiar with, I agree in suggesting at least Homer's Iliad, Aristotle's Nicomachean ethics, and Dante's Comedy [10].

The Iliad provides a wide knowledge of medicine, stimulating a reflection about the strongest desires of mankind (longing for home, celebrity, and reputation) and about mortality. The Nicomachean ethics could help the doctor to properly examine the nature of the good and the concept of medical ethics. The Divine Comedy is an incitement not to consider the patient in isolation from his/ her environment, which includes historic, scientific, moral, and artistic perspectives [10].

In addition to these masterpieces of Classic literature, doctors could adopt also Bulgakov, Céline, Pirandello, Pennac as coaches in this pleasant and natural exercise.

The reading of the book Paula (1994) by Isabel Allende [11], for instance, is extremely useful from this point of 
view: Paula, the writer's daughter, was affected by porphyria, which led her to death. The book starts as a letter to Paula, while Isabel stayed at her bedside in the hospital, then developing into the narrative of the darkest experience of her life: "Each morning I scour the hallways of the sixth floor chasing the specialist in order to investigate on new details. This man has your life in his hands and I don't trust him, he comes and goes like a draft, absent-minded and hurried, giving me boring explanations about enzymes, and giving me copies of articles on your disease, which I try to read, but which I don't understand. He seems more interested in basting his computer's statistics and his laboratory's formulas than in your crucified body lying on this bed".

This lesson for life is addressed to doctors, who are, like all other human beings, impressively shaped by the company they hang out with. If physicians spend all their time with scientific journals and textbooks, they will look like the specialist, described by Isabel Allende. But medical quality requires human quality, and the human aspect of the physician requires to be nourished as the scientific and technical ones.

Actually, a medical student ought to be educated to read different literature, in order to develop and foster the skills, he will use in his future everyday practice. Reading different literature improves in fact the empathic curiosity, which permits to a clinician never to consider a case "closed". Reading different literature helps one to learn to listen.

Conflict of interest None.

\section{References}

1. Cervellin G, Borghi L, Lippi G (2014) Do clinicians decide relying primarily on Bayesians principles or on Gestalt perception? Some pearls and pitfalls of Gestalt perception in medicine. Intern Emerg Med. doi:10.1007/s11739-014-1049-8

2. Kienle GS, Kiene H (2011) Clinical judgement and the medical profession. J Eval Clin Pract 17:621-627

3. Koontz NA, Gunderman RB (2008) Gestalt theory: implications for radiology education. Am J Radiol 190:1156-1160

4. Cabanis PJG (1798) Du degree de certitude de la Médecine. chez Firmin Didot, Paris

5. Lipps T (1883) Grundtatsachen des Seelenlebens. Cohen, Bonn

6. Slawson DC, Shaughnessy AF, Bennett JH (1994) Becoming a medical information master: feeling good about not knowing everything. J Fam Pract 38(5):505-513

7. Drew T, Evans K, Võ ML, Jacobson FL, Wolfe JM (2013) Informatics in radiology: what can you see in a single glance and how might this guide visual search in medical images? Radiographics 33(1):263-274

8. Terzani T (2004) Un altro giro di giostra. Longanesi, Milano

9. Upton J, Janeka I, Ferraro N (2014) The whole is more than the sum of its parts: aristotle, metaphysical. J Craniofac Surg 25(1):59-63

10. Gunderman R (2013) 7 classics every doctor should read. The Atlantic

11. Allende I (1994) Paula. Plaza \& Janés, Barcelona 